\title{
Simple and rapid mechanochemical synthesis of lactide and 3S- (isobutyl)morpholine-2,5-dione based random copolymers using DBU and Thiourea
}

\author{
Tobias F. Burton, ${ }^{\mathrm{a}}$ Julien Pinaud, ${ }^{\mathrm{a}}$ Nicolas Pétry, ${ }^{\mathrm{b}}$ Frédéric Lamaty ${ }^{\mathrm{b}}$ and Olivia Giania ${ }^{*}$ \\ a ICGM, Univ Montpellier, CNRS, ENSCM, 34000 Montpellier, France \\ b IBMM, Univ Montpellier, CNRS, ENSCM, 34000 Montpellier, France
}

\section{Experimental section}

\section{Materials}

Dichloromethane (DCM) and toluene were dried using an Inert Puresolv Micro apparatus equipped with activated alumina columns. 2-Methyltetrahydrofuran (MeTHF) was dried using $4 \AA$ molecular sieves. Anhydrous 1,3dioxolane (>99.5\%) was purchased from Sigma-Aldrich, used as received and stored under nitrogen. All other solvents were purchased as reagent grade and used as received. Deuterated solvent $\mathrm{CDCl}_{3}(99.8$ atom $\% \mathrm{D}, 0.05$ $\%$ vol TMS) was purchased from Sigma Aldrich, used as received and stored in a fridge. L-Leucine $(>98 \%)$, chloroacetyl chloride (> $98 \%$ ), triethylamine (> $99.5 \%$ ), benzyl alcohol (99.8\%), 1,8-diazabicyclo[5.4.0]undec7-ene (>99\%), benzoic acid (99\%), cyclohexylamine ( $>98 \%$ ), 3,5-bis(trifluoromethyl)phenyl isothiocyanate (> $98 \%), \mathrm{NaHCO}_{3}$ (reagent grade) and $\mathrm{MgSO}_{4}$ (Redi-Dri $\left.{ }^{\circledR}\right)$. TU was prepared as described in the literature. ${ }^{1}( \pm)$ Lactide (> $99 \%)$, a racemic mixture of $(+)$-lactide and (-)-lactide, was purchased from TCI Chemicals and recrystallized twice from ethyl acetate. MD was prepared as described in the literature. ${ }^{2}{ }^{1} \mathrm{H}-\mathrm{NMR}\left(\mathrm{CDCl}_{3}, 600\right.$ $\mathrm{MHz}): \delta=7.54(\mathrm{NH}, \mathrm{s}), 4.75\left(\mathrm{O}-\mathrm{CH}_{2}-\mathrm{CO}, \mathrm{s}\right), 4.15(\mathrm{CO}-\mathrm{CH}-\mathrm{NH}, \mathrm{m}), 1.91 / 1.63\left(\mathrm{CH}-\mathrm{CH}_{2}-\mathrm{CH}-\left(\mathrm{CH}_{3}\right)_{2}, \mathrm{~m}\right)$ and 1.01/0.97 ( $\mathrm{CH}_{3}$, dd). ${ }^{13} \mathrm{C}-\mathrm{NMR}\left(\mathrm{CDCl}_{3}, 600 \mathrm{MHz}\right): \delta=167.3(\mathrm{NH}-\mathrm{CO}-), 166.3(\mathrm{O}-\mathrm{CO}), 67.5\left(\mathrm{O}-\mathrm{CH}_{2}-\mathrm{CO}\right), 51.9$ (NH-CH), $41.6\left(\mathrm{CH}-\mathrm{CH}_{2}-\mathrm{CH}\right), 24.3\left(\left(\mathrm{CH}_{3}\right)_{2}-\mathrm{CH}-\mathrm{CH}_{2}\right)$ and 22.9/21.4 $\left(\mathrm{CH}_{3}\right)$.

${ }^{1} \mathrm{H},{ }^{13} \mathrm{C}$ and DOSY NMR analysis were carried out on a $600 \mathrm{MHz}$ Bruker Avance III HD spectrometer equipped with a CryoProbe Prodigy. For DOSY-NMR, values of diffusion coefficient were determined by averaging the coefficient of each spot in $1 \mathrm{D}$ mode. The characteristic peaks of $\mathrm{CHCl}_{3}$ at $7.26 \mathrm{ppm}$ (in ${ }^{1} \mathrm{H}-\mathrm{NMR}$ ) and at $77.16 \mathrm{ppm}$ (in ${ }^{13} \mathrm{C}-\mathrm{NMR}$ ) were used to calibrate the analysis. The notations employed to describe the NMR spectra are abbreviated as follows: $s$ (singlet), $d$ (doublet), $t$ (triplet), $q$ (quadruplet), $m$ (multiplet), dd (doublet of doublets), dm (doublet of multiplets) and br (broad signal). MD monomer conversions were calculated by comparing the area of the $\mathrm{CH}_{3}$ peaks at 0.98 ppm to the area of the $\mathrm{CH}_{2}$ and $\mathrm{CH}$ peaks between 4.2 and $4.9 \mathrm{ppm}$. LA monomer conversions were calculated by comparing the area of the polymer $\mathrm{CH}$ peak at $5.2 \mathrm{ppm}$ to the area of the monomer $\mathrm{CH}$ peak at $5.0 \mathrm{ppm}$. The average degree of polymerisation and $\mathrm{Mn}_{\mathrm{NMR}}$ for PMDs were determined by comparing the area of the benzyl peak at $5.1 \mathrm{ppm}$ to the area of the precipitated polymer backbone peaks between 4.2 and $4.9 \mathrm{ppm}$. For PLA and P(MD-co-LA), the degree of polymerisation cannot be calculated in this fashion due to peak overlap. Size exclusion chromatography (SEC) was performed at $30^{\circ} \mathrm{C}$ in THF with a flow rate of $1.0 \mathrm{~mL} \cdot \mathrm{min}^{-1}$. Two $5 \mu \mathrm{m}$ PLgel Mixed D columns were used with a $5 \mu \mathrm{m}$ PLgel guard column. A Varian 390-LC refractive index detector (RID) was used as the detector. Universal calibration was done using Agilent Technologies EasiVial polystyrene (PS) standards, using the intrinsic viscosities issued by the supplier. Concentrations of approximately $5 \mathrm{mg} \mathrm{mL}^{-1}$ were used for the polymer samples. Differential scanning calorimetry (DSC) analysis of polymers was performed using a NETZSCH DSC200F3 calorimeter. Constant calibration was performed with biphenyl, indium, bismuth, zinc and caesium chloride standards. Nitrogen was used as the purge gas. Approximately $10 \mathrm{mg}$ of polymer sample were placed in pierced aluminium pans and heated to $180^{\circ} \mathrm{C}$ then cooled to $20^{\circ} \mathrm{C}$ with a rate of $5{ }^{\circ} \mathrm{C} \cdot \mathrm{min}^{-1}$ with the intention of erasing the thermal history. The thermal properties were then recorded with a heating rate of $10{ }^{\circ} \mathrm{C} \cdot \mathrm{min}^{-1}$ between $20{ }^{\circ} \mathrm{C}$ and $180{ }^{\circ} \mathrm{C}$. Vibrational milling reactions were carried out in a Retsch Mixer Mill MM 400 with $10 \mathrm{~mL}$ reaction vessels made of PTFE, stainless steel or $\mathrm{ZrO}_{2}$ matched with a 10- or 5- mm ball made of either stainless steel, PTFE coated stainless steel or $\mathrm{ZrO}_{2}$. 


\section{Methods}

\section{- MD mechanochemical homopolymerization}

The following procedure corresponds to the synthesis of PMD with a target DP of 50 (PMD11).

A $10 \mathrm{~mL}$ zirconium oxide reactor was loaded with $200 \mathrm{mg}$ of MD ( $1.17 \mathrm{mmol}, 50$ equiv.), $43 \mathrm{mg}$ of TU (0.11 mmol, 5 equiv.) and one $10 \mathrm{~mm}$ zirconium ball. To this was added $70 \mathrm{mg}$ of a solution containing $\mathrm{BnOH}(0.43$ $\left.\mathrm{mmol} \mathrm{L}^{-1}\right)$ and DBU $\left(0.43 \mathrm{mmol} \mathrm{L}^{-1}\right)$ in DCM $(0.023 \mathrm{mmol}$ of both DBU and BnOH, 1 equiv.). The reactor was then sealed and subjected to vibratory milling at $30 \mathrm{~Hz}$ for the set amount of time. The polymerisation was then quenched by adding $0.2 \mathrm{~mL}$ of a $0.06 \mathrm{~mol} \mathrm{~L}^{-1}$ benzoic acid solution followed by 30 seconds of ball milling. The resulting powder was dissolved in a minimal amount of chloroform and precipitated in cold diethyl ether. A white solid was obtained and dried in vacuo. ${ }^{1} \mathrm{H}-\mathrm{NMR}\left(\mathrm{CDCl}_{3}, 600 \mathrm{MHz}\right): \delta=7.76-7.88(\mathrm{NH}, \mathrm{br}), 7.35(\mathrm{Ar}, \mathrm{br}), 5.16$ $\left(\mathrm{Ar}-\mathrm{CH}_{2}-\mathrm{CO}, \mathrm{s}\right), 4.73 \& 4.57\left(\mathrm{O}-\mathrm{CH}_{2}-\mathrm{CO}, \mathrm{br}\right), 4.34(\mathrm{CO}-\mathrm{CH}-\mathrm{NH}, \mathrm{br}), 1.86 \& 1.70\left(\mathrm{CH}-\mathrm{CH}_{2}-\mathrm{CH}-\left(\mathrm{CH}_{3}\right)_{2}\right.$, br) and $0.98 \& 0.92\left(\mathrm{CH}_{3}, \mathrm{dd}\right) .{ }^{13} \mathrm{C}-\mathrm{NMR}\left(\mathrm{CDCl}_{3}, 600 \mathrm{MHz}\right): \delta=171.5(\mathrm{O}-\mathrm{CO}-), 169.4(\mathrm{NH}-\mathrm{CO}), 130.2 / 128.7 / 128.2$ $(\mathrm{Ar}), 66.9\left(\mathrm{Ar}-\mathrm{CH}_{2}-\mathrm{CO}\right), 62.8\left(\mathrm{O}-\mathrm{CH}_{2}-\mathrm{CO}\right), 52.3(\mathrm{NH}-\mathrm{CH}), 38.9\left(\mathrm{CH}-\mathrm{CH}_{2}-\mathrm{CH}\right), 24.9\left(\left(\mathrm{CH}_{3}\right)_{2}-\mathbf{C H}-\mathrm{CH}_{2}\right)$ and 22.9/21.7 $\left(\mathrm{CH}_{3}\right)$.

\section{- LA mechanochemical homopolymerization}

The following procedure corresponds to the synthesis of PLAs with a target DP of 50 (PLA1).

A $10 \mathrm{~mL}$ zirconium oxide reactor was loaded with $170 \mathrm{mg}$ of LA, $1.17 \mathrm{mmol}, 50$ equiv., $43 \mathrm{mg}$ of TU $(0.11 \mathrm{mmol}$, 5 equiv.) and one $10 \mathrm{~mm}$ zirconium ball. To this was added $70 \mathrm{mg}$ of a solution containing $\mathrm{BnOH}(0.43 \mathrm{mmol}$ $\left.\mathrm{L}^{-1}\right)$ and DBU $\left(0.43 \mathrm{mmol} \mathrm{L}^{-1}\right)$ in DCM $(0.023 \mathrm{mmol}$ of both DBU and $\mathrm{BnOH}, 1$ equiv. $)$. The reactor was then sealed and subjected to vibratory milling at $30 \mathrm{~Hz}$ for the set amount of time. The polymerisation was then quenched by adding $0.2 \mathrm{~mL}$ of a $0.06 \mathrm{~mol} \mathrm{~L}^{-1}$ benzoic acid solution followed by 30 seconds of ball milling. The resulting powder was dissolved in a minimal amount of chloroform and precipitated in cold water. A white solid was obtained and dried in vacuo. ${ }^{1} \mathrm{H}-\mathrm{NMR}\left(\mathrm{CDCl}_{3}, 600 \mathrm{MHz}\right): \delta: 7.34(\mathbf{A r}), 5.15\left(\mathrm{CH}\right.$ and $\mathrm{Ar}-\mathrm{CH}_{2}$, br) and 1.57 $\left(\mathrm{CH}_{3}\right.$, br). ${ }^{13} \mathrm{C}-\mathrm{NMR}\left(\mathrm{CDCl}_{3}, 600 \mathrm{MHz}\right): \delta: 169.8(\mathrm{CO}), 128.8 / 128.4(\mathbf{A r}), 69.4(\mathbf{C H}), 66.9\left(\mathrm{Ar}^{\left.-\mathrm{CH}_{2}\right)}\right.$ and 16.9 $\left(\mathrm{CH}_{3}\right)$.

\section{- MD and LA mechanochemical copolymerization}

The following procedure corresponds to the synthesis the copolymer C3 containing 25 PMD and 25 PLA repeating units.

A $10 \mathrm{~mL}$ zirconium oxide reactor was loaded with $110 \mathrm{mg}$ of MD ( $0.64 \mathrm{mmol}, 25$ equiv.), $94 \mathrm{mg}$ of LA (0.65 mmol, 25 equiv.), $48 \mathrm{mg}$ of TU ( $0.13 \mathrm{mmol}, 5$ equiv.) and one $10 \mathrm{~mm}$ zirconium ball. To this was added $70 \mathrm{mg}$ of a solution containing BnOH $\left(0.43 \mathrm{mmol} \mathrm{L}^{-1}\right)$ and $\mathrm{DBU}\left(0.43 \mathrm{mmol} \mathrm{L}^{-1}\right)$ in DCM $(0.026 \mathrm{mmol}, 1$ equiv. of both $\mathrm{DBU}$ and $\mathrm{BnOH}$ ). The reactor was then sealed and subjected to vibratory milling at $30 \mathrm{~Hz}$ for the set amount of time. The polymerisation was then quenched by adding $0.2 \mathrm{~mL}$ of a $0.06 \mathrm{~mol} \mathrm{~L}^{-1}$ benzoic acid solution followed by 30 seconds of ball milling. The resulting powder was dissolved in a minimal amount of chloroform and precipitated in cold diethyl ether. A white solid, corresponding to the copolymer, was obtained and dried in vacuo. ${ }^{1} \mathrm{H}-\mathrm{NMR}\left(\mathrm{CDCl}_{3}, 600 \mathrm{MHz}\right): \delta: 7.73(\mathrm{NH}, \mathrm{br}), 7.36(\mathbf{A r}), 5.17$ (CH LA), 4.82-4.51 (O-CH $\mathbf{C H}_{2}-\mathrm{CO}$ and $\mathrm{Ar}-$ $\mathrm{CH}_{2}$, br), 4.35 (NH-CH-CO, br), 1.82-1.72 ( CH-CH $\left.\mathbf{C H}_{2}-\mathrm{CH}\left(\mathrm{CH}_{3}\right)_{2}\right), 1.58\left(\mathrm{CH}_{3} \mathrm{LA}, \mathrm{b}\right)$ and $0.95\left(\mathrm{CH}_{3} \mathrm{MD}, \mathrm{br}\right) .{ }^{13} \mathrm{C}-$ NMR $\left(\mathrm{CDCl}_{3}, 600 \mathrm{MHz}\right): \delta=171.5$ (O-CO- (MD)), 169.3 (CO (LA) and NH-CO-), 128.6/130.2/133.5 (Ar), 70.1/69.1 (CO-CH (LA)), $66.9\left(\mathrm{Ar}-\mathrm{CH}_{2}\right), 62.8\left(\mathrm{CO}-\mathrm{CH}_{2}-\mathrm{O}\right), 52.3 / 50.5(\mathrm{NH}-\mathrm{CH}), 40.3 / 39.3\left(\mathrm{CH}-\mathrm{CH}_{2}-\mathrm{CH}\right), 24.9$ $\left(\left(\mathrm{CH}_{3}\right)_{2}-\mathrm{CH}-\mathrm{CH}_{2}\right), 22.9 / 21.7\left(\mathrm{CH}_{3}(\mathrm{MD})\right)$ and $16.8\left(\mathrm{CH}_{3}(\mathrm{LA})\right)$. 
- Polymer milling

The following procedure corresponds to the ball-milling of PMD in the presence of $\mathrm{DBU}, \mathrm{BnOH}, \mathrm{TU}$ and DCM.

A $10 \mathrm{~mL}$ zirconium oxide reactor was loaded with $200 \mathrm{mg}$ of PMD (1.17 mmol, 50 equiv. of MD repeating units), $43 \mathrm{mg}$ of TU $(0.11 \mathrm{mmol}, 5$ equiv.) and one $10 \mathrm{~mm}$ zirconium ball. To this was added $70 \mathrm{mg}$ of a solution containing BnOH $\left(0.43 \mathrm{mmol} \mathrm{L}^{-1}\right)$ and DBU $\left(0.43 \mathrm{mmol} \mathrm{L}^{-1}\right)$ in DCM $(0.023 \mathrm{mmol}$ of both DBU and $\mathrm{BnOH}, 1$ equiv.). The reactor was then sealed and subjected to vibratory milling at $30 \mathrm{~Hz}$ for 30 minutes. The reaction was then quenched by adding $0.2 \mathrm{~mL}$ of a $0.06 \mathrm{~mol} \mathrm{~L}^{-1}$ benzoic acid solution followed by 30 seconds of ball milling. The resulting paste was dissolved in a minimal amount of chloroform and readily precipitated in cold diethyl ether. A white solid was obtained, dried in vacuo and analysed by SEC.

\section{Supplementary Tables}

Table S1: MechaROP of MD with different ratios of MD/BnOH (n:1:1:5 (MD:BnOH:DBU:TU)).

\begin{tabular}{|c|c|c|c|c|c|c|c|}
\hline Name & $\begin{array}{c}\text { MD } \\
\text { (equiv) }\end{array}$ & $\begin{array}{l}\text { Time } \\
\text { (min) }\end{array}$ & $\begin{array}{l}\text { Conv. } \\
(\%)^{\mathrm{a}}\end{array}$ & $\begin{array}{l}\text { Mn,TARGET } \\
\left(\mathrm{kg} \mathrm{mol}^{-1}\right)^{b}\end{array}$ & $\underset{\left(\mathrm{kg} \mathrm{mol}^{-1}\right)^{\mathrm{c}}}{\mathrm{CALC}}$ & $\begin{array}{c}\text { Mn, }, \text { SEC } \\
\left(\mathrm{kg} \mathrm{mol}^{-1}\right)^{\mathrm{d}}\end{array}$ & $\boldsymbol{\theta}$ \\
\hline PMD18 & 100 & 15 & 53 & 17.3 & 9.2 & 8.6 & 1.43 \\
\hline PMD19 & 100 & 30 & 46 & 17.3 & - & - & - \\
\hline PMD20 & 150 & 15 & 22 & 25.9 & 6.0 & 3.2 & 1.45 \\
\hline PMD21 & 150 & 30 & 25 & 25.9 & 6.5 & 3.0 & 1.40 \\
\hline PMD22 & 25 & 10 & 99 & 4.4 & 4.4 & 4.2 & 1.28 \\
\hline PMD23 & 15 & 10 & 99 & 2.7 & 2.7 & 2.5 & 1.30 \\
\hline
\end{tabular}

Ball-milling at $30 \mathrm{~Hz}$ in a $\mathrm{ZrO}_{2}$ reactor with one $10 \mathrm{~mm} \mathrm{ZrO}_{2}$ ball. $\eta_{(\mathrm{DCM})}=0.2 \mu \mathrm{lmg}^{-1}$. * : No TU; ${ }^{a}$ : Determined via ${ }^{l} H$-NMR spectroscopy; ${ }^{b}: M n,_{T A R G E T}=n_{M D} / n_{B n O H} \times M_{M D}+M_{B n O H} ;{ }^{c}: M n,_{C A L C}=n_{M D} / n_{B n O H} \times c o n v . \times M_{M D}+$ $M_{B n O H}{ }^{d}$ : Determined via SEC in THF using PS standards.

Table S2: Ball-milling of different purified PMDs in various conditions.

\begin{tabular}{|c|c|c|c|c|c|c|c|}
\hline \multirow{2}{*}{$\begin{array}{l}\text { Preparation } \\
\text { method }\end{array}$} & \multicolumn{3}{|c|}{ Milling conditions } & \multicolumn{2}{|c|}{ Before milling } & \multicolumn{2}{|c|}{ After milling } \\
\hline & $\begin{array}{l}\text { Solvent ; } \\
\eta\left(\mu l \mathrm{mg}^{-1}\right)\end{array}$ & $\begin{array}{l}\text { Time } \\
(\mathrm{min})\end{array}$ & Other & $\begin{array}{c}\mathrm{Mn}, \mathrm{SEC} \\
\left(\mathrm{kg} \mathrm{mol}^{-1}\right)^{\mathrm{a}}\end{array}$ & $\boldsymbol{\theta}$ & $\begin{array}{c}\mathrm{Mn}, \text { SEC } \\
\left(\mathrm{kg} \mathrm{mol}^{-1}\right)^{\mathrm{a}}\end{array}$ & $\boldsymbol{H}$ \\
\hline MechaROP & - & 15 & - & 8.6 & 1.43 & 1.6 & 1.55 \\
\hline MechaROP & DCM : 0,2 & 15 & - & 8.6 & 1.43 & 3.4 & 1.75 \\
\hline Solution & - & 15 & - & 44.4 & 1.49 & 12.6 & - \\
\hline Solution & DCM : 0,2 & 30 & $\begin{array}{c}1: 1: 5 \\
\text { BnOH: } \\
\text { DBU:TU }\end{array}$ & 7.1 & 1.14 & 3.16 & 2.02 \\
\hline
\end{tabular}

Ball-milling at $30 \mathrm{~Hz}$ in a $\mathrm{ZrO}_{2}$ reactor with one $10 \mathrm{~mm} \mathrm{ZrO}_{2}$ ball. ${ }^{a}$ : Determined via SEC in THF using PS standards.

Table S3: MechaROP of LA with n:1:1:5 (LA:BnOH:DBU:TU).

\begin{tabular}{|c|c|c|c|c|c|c|}
\hline Name & $\begin{array}{c}\text { LA } \\
\text { (equiv) }\end{array}$ & $\begin{array}{l}\text { Time } \\
(\mathrm{min})\end{array}$ & $\begin{array}{l}\text { Conv. } \\
(\%)^{\mathrm{a}}\end{array}$ & $\begin{array}{l}\text { Mn,TARGET } \\
\left(\mathrm{kg} \mathrm{mol}^{-1}\right)^{\mathrm{b}}\end{array}$ & $\begin{array}{c}\mathrm{Mn}, \mathrm{SEC} \\
\left(\mathrm{kg} \mathrm{mol}^{-1}\right)^{\mathrm{c}}\end{array}$ & $\boldsymbol{\oplus}$ \\
\hline PLA1 & 50 & 15 & 99 & 7.3 & 6.9 & 1.27 \\
\hline PLA2 & 35 & 10 & 99 & 5.2 & 5.5 & 1.16 \\
\hline PLA3 & 25 & 10 & 99 & 3.7 & 4.0 & 1.26 \\
\hline PLA4* & 50 & 15 & 99 & 7.3 & 4.8 & 1.47 \\
\hline
\end{tabular}

Ball-milling at $30 \mathrm{~Hz}$ in a $\mathrm{ZrO}_{2}$ reactor with one $10 \mathrm{~mm} \mathrm{ZrO}_{2}$ ball. $\eta_{(\mathrm{DCM})}=0.2 \mu \mathrm{lmg}^{-1}$. * : No TU; ${ }^{*}$ : Determined via ${ }^{l} H$-NMR spectroscopy; ${ }^{b}:$ Mn, TARGET $=n_{L A} / n_{B n O H} \times M_{L A}+M_{B n O H} ;{ }^{c}:$ Determined via SEC in THF using PS standards. 
Table S4: Determination of the theoretical glass transition temperatures (Tg, FOX) of copolymers C1, C2 and C3 using the Fox equation.

\begin{tabular}{ccccccc}
\hline Sample & $\mathbf{m}_{\text {LA }}$ & $\mathbf{m}_{\text {MD }}$ & $\mathbf{w}_{\text {LA }}$ & $\mathbf{w}_{\mathbf{M D}}$ & $\begin{array}{c}\text { Tg,Fox } \\
\left({ }^{\circ} \mathbf{C}\right)\end{array}$ & $\begin{array}{c}\text { Tg,DSC } \\
\left({ }^{\circ} \mathbf{C}\right)\end{array}$ \\
\hline C1 & 0.77 & 0.23 & 0.74 & 0.26 & 44.4 & 43.9 \\
\hline C2 & 0.31 & 0.69 & 0.27 & 0.73 & 48.7 & 51.1 \\
\hline C3 & 0.52 & 0.48 & 0.48 & 0.52 & 46.7 & 46.7 \\
\hline PLA1 & 1 & 0 & 1 & 0 & - & 42.3 \\
\hline PMD11 & 0 & 1 & 0 & 1 & - & 51.6 \\
\hline
\end{tabular}

$m X$ : Molar fraction of motifs $X$ in copolymer; $w X$ : Weight fraction of motifs $X$ in copolymer.

Table S5: Glass transition temperatures of PMD, PLA and 50:50 mixtures of PLA and PMD before and after milling. Measured by DSC.

\begin{tabular}{cc}
\hline Sample & Tg,DSC $\left({ }^{\circ} \mathbf{C}\right)$ \\
\hline PLA & 42,3 \\
\hline PMD & 53,0 \\
\hline PLA + PMD before milling & 41,$8 ; 53,3$ \\
\hline PLA + PMD after milling & 45,3 \\
\hline
\end{tabular}

\section{Supplementary figures}
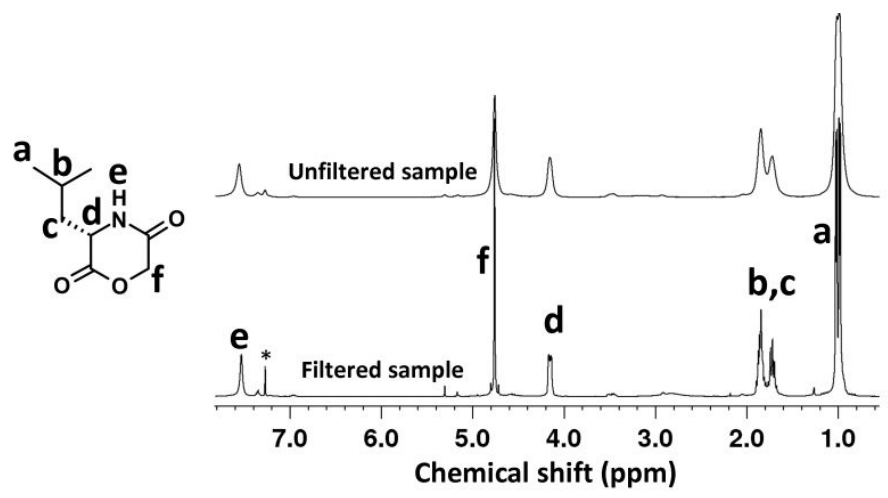

Figure S1: ' $\mathrm{H}$-NMR spectra of the crude product obtained from PMD2 in CDCl. Top: Unfiltered; $\underline{\text { Bottom: }}$ Filtered through cotton. *: Residual $\mathrm{CHCl}_{3}$ from deuterated solvent. 

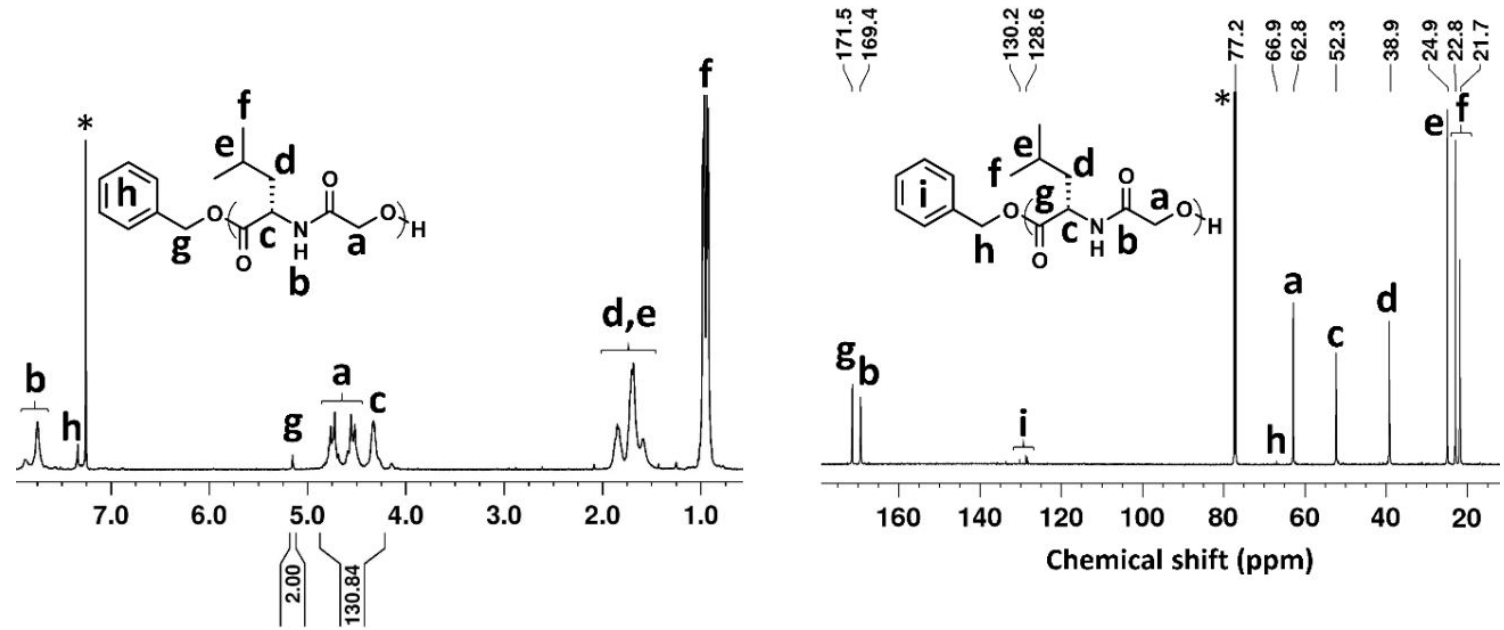

Figure S2: ${ }^{1} \mathrm{H}-\mathrm{NMR}$ (left) and ${ }^{13} \mathrm{C}-\mathrm{NMR}$ (right) spectra of polymer recovered from $\mathrm{PMD} 11 \mathrm{in} \mathrm{CDCl}_{3}$.

*: Residual $\mathrm{CHCl}_{3}$ from deuterated solvent.

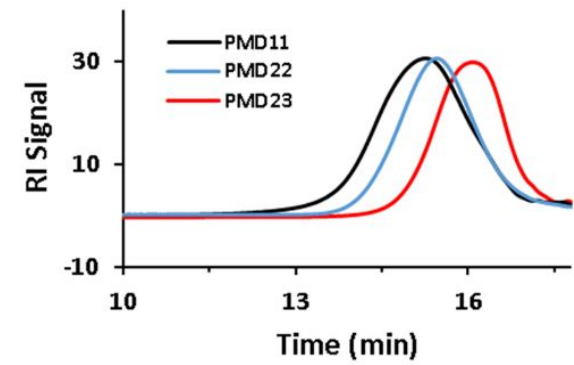

Figure S3: Size exclusion chromatograms of polymers resulting from PMD11 (black), PMD22 (blue) and PMD23 (red).

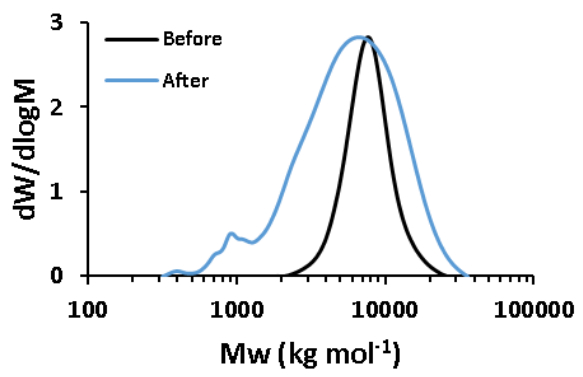

Figure S4: Size exclusion chromatograms of a PMD synthesised via the solution based ROP before (black) and after (blue) 30 minutes of milling at $30 \mathrm{~Hz}$ in a $\mathrm{ZrO}_{2}$ reactor with one $10 \mathrm{~mm}$ ball in the presence of DBU (1 equiv.) and $T U$ (5 equiv.). $\eta_{(D C M)}=0.2 \mu l \mathrm{mg}^{-1}$.

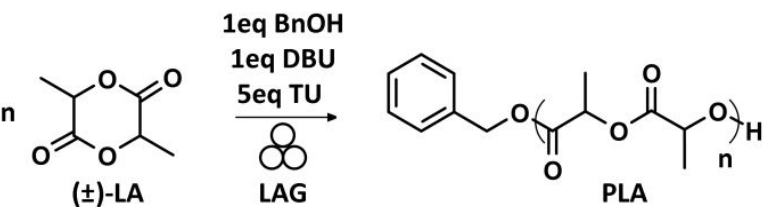

Figure S5: MechaROP of LA. 

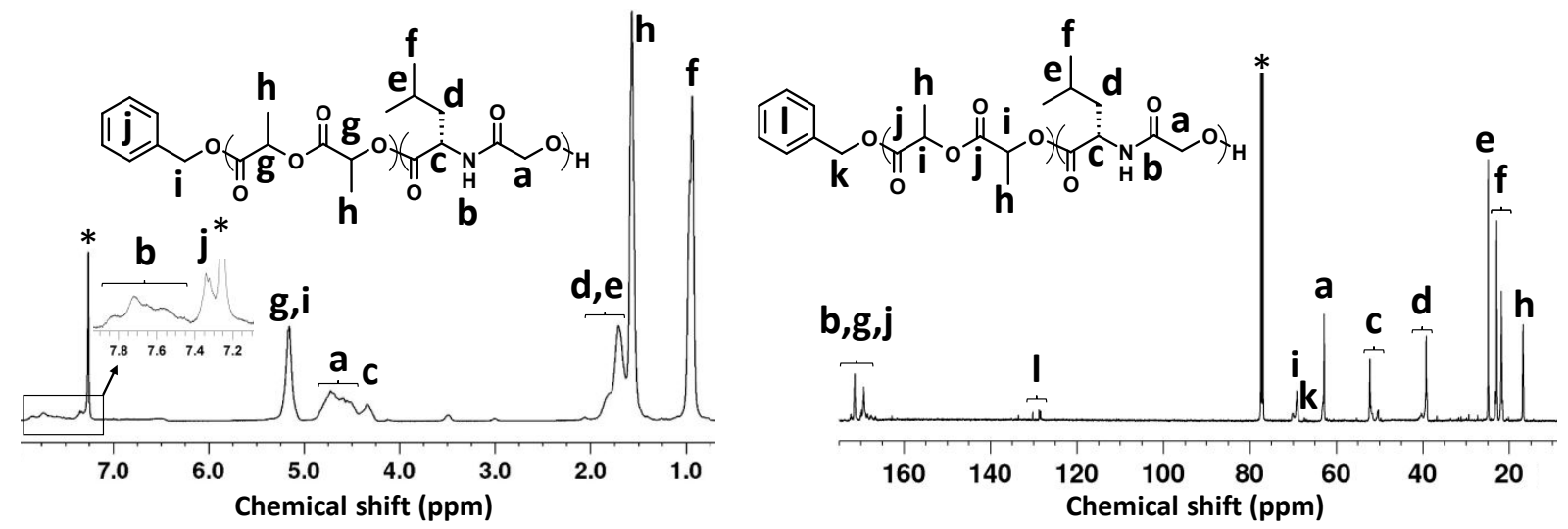

Figure S6: ${ }^{1} \mathrm{H}$ NMR (left) and ${ }^{13} \mathrm{C}-\mathrm{NMR}$ (right) spectra of precipitated copolymer $\mathrm{C} 3$ in $\mathrm{CDCl}_{3}$. *: Residual $\mathrm{CHCl}_{3}$ from deuterated solvent.

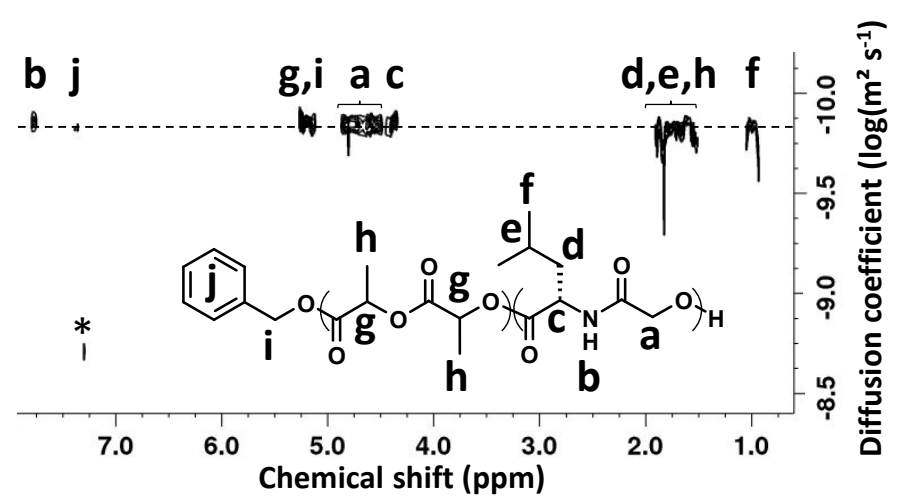

Figure S7: DOSY-NMR spectrum of $\mathrm{C} 3$ in $\mathrm{CDCl}_{3}$. *: Residual $\mathrm{CHCl}_{3}$ from deuterated solvent.

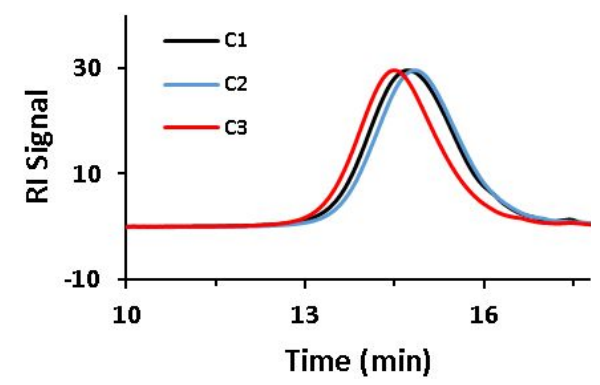

Figure S8: Size exclusion chromatograms of copolymers obtained from C1 (black), C2 (blue) and C3 (red).

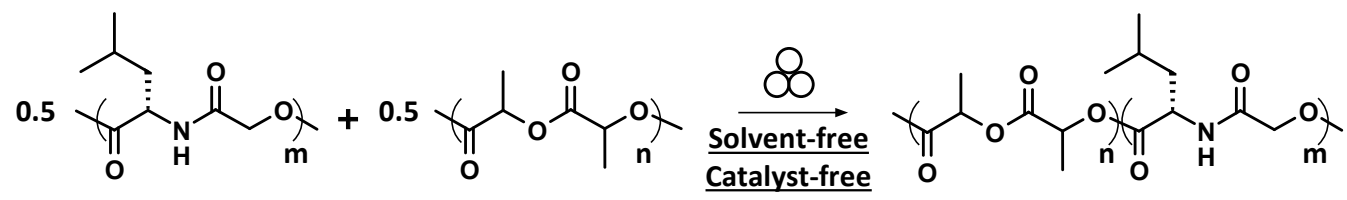

Figure S9: Proposed mechanochemical synthesis of $P(L A-c o-M D)$ via ester-ester interchange/transesterification reactions of PLA and PMD. 


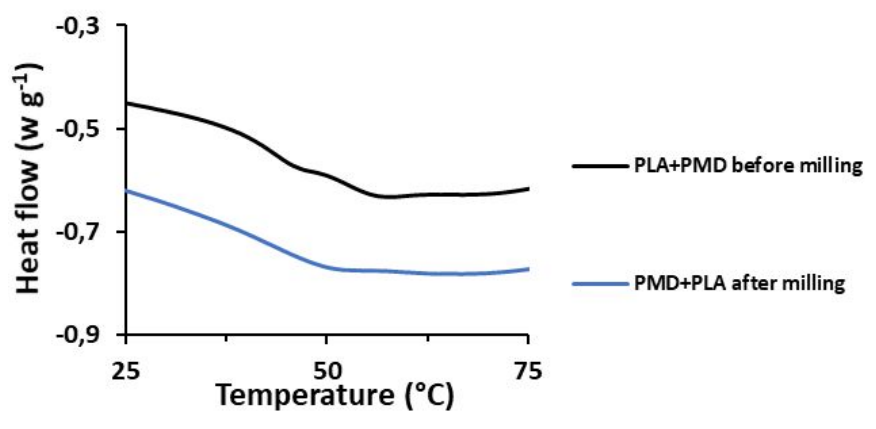

Figure S10: Differential scanning calorimetry thermograms of a 50:50 mixture of PMD and PLA before (black) and after milling (blue).

\section{References}

(1) Pratt, R. C.; Lohmeijer, B. G. G.; Long, D. A.; Lundberg, P. N. P.; Dove, A. P.; Li, H.; Wade, C. G.; Waymouth, R. M.; Hedrick, J. L., Macromolecules 2006, 39 (23), 7863-7871.

(2) Burton, T. F.; Pinaud, J.; Giani, O., Macromolecules 2020, 53 (15), 6598-6607. 